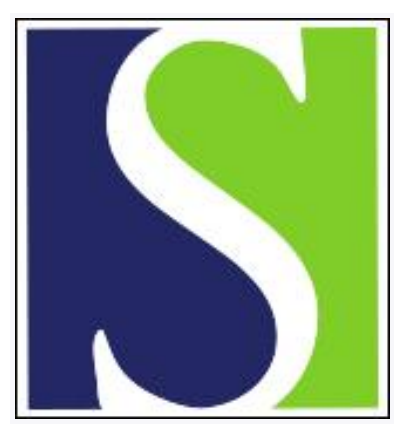

Scand J Work Environ Health 2000;26(6):523-528

https://doi.org/10.5271/sjweh.577

Issue date: Dec 2000

Predictors of first nonfatal occupational injury following employment in a Brazilian steelworks

by Barreto SM, Swerdlow AJ, Schoemaker MJ, Smith PG

The following article refers to this text: 2008;34(6):438-443

Key terms: cohort study; education; steel worker; work-related injury

This article in PubMed: www.ncbi.nlm.nih.gov/pubmed/11201400 


\title{
Predictors of first nonfatal occupational injury following employment in a Brazilian steelworks
}

\author{
by Sandhi M Barreto, PhD, ${ }^{1}$ Anthony J Swerdlow, PhD, ${ }^{2}$ Minouk J Schoemaker, MSc, ${ }^{2}$ \\ Peter G Smith, PhD
}

Barreto SM, Swerdlow AJ, Schoemaker MJ, Smith PG. Predictors of first nonfatal occupational injury following employment in a Brazilian steelworks. Scand J Work Environ Health 2000;26(6):523-528.

\begin{abstract}
Objectives This study investigated the influence of sociodemographic and occupational factors on the risk of 1st injury among Brazilian steelworkers.

Methods Workers 1st employed between 1 January 1977 and 31 December 1985 and still employed on 1 December 1983 were followed from the date of hire until 30 October 1992. Occupational injuries were ascertained from a database. Kaplan-Meier curves for time to 1st injury were calculated for the total cohort and for different subgroups. A multivariate analysis of risk factors for 1 st injury was carried out using the Cox proportional hazards regression model.

Results Forty-one percent of the workers had $\geq 1$ occupational injuries, and $39 \%$ of 1 st injuries occurred in the 1st year of employment. Lacerations, contusions, penetration by foreign bodies, burns, sprains, and fractures constituted the main diagnostic groups. Injuries to the hands, eyes, feet, arms, and legs dominated. Over $5 \%$ of the injured workers were on temporary disability leave (cumulative total 10660 days). The probability for an occupational injury was $16 \%$ for the 1 st year, rising to $25 \%$ in the 2 nd year. The risk of nonfatal injury was highest for laborers [hazard ratio (HR) 1.76, 95\% confidence interval (95\% CI) 1.35-2.29] and employees in the steel mill (HR 1.40, $95 \% \mathrm{CI} 1.21-1.63)$, and inversely related to worker age and educational level. The risk of injury decreased significantly with calendar period of employment.

Conclusions Substantial reductions in nonfatal injuries may reflect changes in work organization, increased automation, and improved safety standards. Knowledge of predictors of work-related injury may contribute to injury prevention strategies, especially among newly employed workers.
\end{abstract}

Key terms cohort study, education, steel workers, work-related injury.

The workplace is a significant contributor to fatal and nonfatal injuries worldwide and an insufficiently appreciated contributor to the total burden of health care costs. In the United States, for instance, estimates of the number of nonfatal work-related injuries range from 6 to 13 million annually $(1-3)$, and the total annual cost of work-related injuries and fatalities has been estimated to be greater than USD 121 billion (4).

In Brazil, occupational injury rates are 2 to 4 times higher than in most industrialized countries (5). In 1996, work-related injuries accounted for $91.2 \%$ of all reported workplace morbidity among the employed urban population, totaling 361755 cases. In the same year, the
National Institute of Social Security spent around USD 5 million on rehabilitation programs for injured workers. Altogether 428072 employees were treated for occupational injury. Of this number $45.2 \%$ had work absences of up to 15 days, $37.3 \%$ had long-term disabilities (loss of more than 15 workdays), $5.9 \%$ had permanent disability, and $1.3 \%$ of the injuries were fatal.

As in many other countries, however, occupational injuries are underreported in Brazil $(5,6)$. The main reason for the underreporting is that the national database (from which the data on occupational injuries derive) excludes public-sector employees and rural, self-employed, and informal or temporary workers.

1 Universidade Federal de Minas Gerais, Centro de Pesquisa René Rachou, Brazil, Brazil.

2 Department of Epidemiology and Population Health, London School of Hygiene \& Topical Medicine, London, Great Britain.

3 Department of Infectious and Tropical Diseases, London School of Hygiene \& Topical Medicine, London, Great Britain.

Reprint requests to: Dr Sandhi M Barreto, Centro de Pesquisa René Rachou / FIOCRUZ, Av. Augusto de Lima 1715, Belo Horizonte, 30.190.002, Brazil, Brazil. [sbarreto@cpqrr.fiocruz.br] 
The risk of injury-related disability seems to increase with the number of injuries a worker has had previously $(7,8)$. Work experience seems also relevant to injury prevention, since injury risk is inversely related to duration of employment $(9,10)$. Identifying personal and occupational predictors of work-related injury may contribute to injury-prevention strategies, especially among newly employed workers. We have tried to assess the influence of social and demographic factors on the risk of 1st injury in the workplace, after taking into account the effect of other relevant factors, such as year of starting employment, place of work, and job category.

\section{Subjects and methods}

The study was carried out using data from a very large steelworks in southeast Brazil, the 2 nd largest steel producer in the country with a work force of about 12500 . A large cohort study had previously been undertaken to investigate the mortality of workers at the plant (1113). This cohort comprised 21816 men employed at the plant at any time between 1 January 1977 and 31 August 1992. Details of the methods used to assemble the cohort and to follow the members have been published elsewhere. (11) In the present study, data from a subset of the cohort were analyzed because sociodemographic information could only be collected for this group. The subset consisted of 6609 workers who began work in the plant between 1 January 1977 and 31 December 1985 and who were still employed in the plant on 1 January 1983 if they had started work in the plant before that date.

We confined the analysis to nonfatal occupational injuries that occurred during the workshift and that resulted directly from a worker's job or to which the worker's job was a contributory factor. The injuries were ascertained using the database of the Occupational Hygiene Department, which contained information for all workers on the date and site of injury, type of tissue damage, number of workdays lost as a result of any reported injury, any sequelae, and other general information about the worker. Information about the injury had been recorded by the plant hygienists on the day of its occurrence. This database was considered to be virtually complete and was used to produce the official report on the occurrence of injuries for the Ministry of Labour.

The cohort members were classified according to their age at the start of employment $(\leq 18,19-25, \geq 26$ years), period of start of employment (1977-1979, $1980-1982,1983-1985)$, educational level $(\leq 4,5-$ $8,9-11, \geq 12$ years of school attendance), and marital status at the time of admission to the plant (single, married, other). Information on job category (professionals and technicians, clerks, and laborers) and place of work at the beginning of work in the steelworks was also used in the analysis. To summarize the data for the statistical analysis, we grouped the place of work into the following 7 major areas based on production flow: administration, research, quality and production control; maintenance; energy supply; cranes and other heavy motor vehicles; cold and hot strip mills; steel mill; and coke and foundry areas.

Workers were followed from the date they started work at the plant to the time they left the plant, their death, or 30 October 1992, whichever was earliest. Kaplan-Meier curves for time to 1st injury were calculated for the total cohort and for subgroups by age, period of 1 st employment, school level, marital status at entry to work, occupational group, and place of work. The curves were tested for heterogeneity using the log-rank test. A multivariate analysis was carried out using the Cox proportional hazards regression model to assess the effect of the different factors on time to 1 st occupational injury. The assumption of proportional hazards was checked by plotting the logarithm of the cumulative baseline rate against the logarithm of time since 1 st employment by the explanatory variable and assessing whether the lines were parallel (14). The analysis was conducted using Stata statistical software (15).

\section{Results}

As the cohort consisted of workers who had entered the industry between 1977 and 1985, the period of followup varied from 7 to 16 years. Data were missing for 116 $(1.7 \%)$ workers, and hence 6493 men were included in the analyses. A total of 2686 workers had at least 1 injury at the worksite, and 1104 had $\geq 2$ injuries. Table 1 shows the distribution of the workers according to the number of occupational injuries recorded.

Among the 2686 workers with $\geq 1$ occupational injuries, the 1st occupational injury led to loss of workdays for 143 workers and resulted in permanent disability for 8 of these workers. Altogether 10660 (median 29) days of work were lost as a result of 1 st injuries, and the industry paid the equivalent of 9260 days in compensation for permanent disability. The remaining 2543 first-time injured workers were able to return to work on the following workday.

Lacerations, cuts, and scrapes accounted for $36 \%$ of the 1 st injuries followed by contusions and hematomas, foreign bodies and burns, chemical burns, and scalds (table 2). Hands were the anatomic sites sustaining the most first-time injuries, followed by eyes, feet, arms, and legs (table 3).

The results of the Kaplan-Meier analyses of time to 1 st accident are given in figure 1 , which shows the pro- 
portion of workers remaining injury-free at different times since 1 st employment. Sixteen percent $(\mathrm{N}=1055)$ of the cohort had an occupational injury during their 1 st year of employment, the proportion remaining injury-free being $84 \%$ [95\% confidence interval $(95 \%$ CI) $83-$ $85 \%]$. At the end of the 2 nd year of employment the percentage of those who had not had any injury decreased to $75 \%(95 \%$ CI $74-77 \%$ ), after 7 years it was $60 \%$ $(95 \%$ CI $64-66 \%)$, and after 15 years it was $53 \%(95 \%$ CI $51-55 \%$ ) (figure 1a).

The risk of injury reduced substantially with calendar period of employment (figure 1b). The percentage of workers who were injury-free after 1 year of employment was $79 \%(95 \%$ CI $78-81 \%$ ) for workers who started work during $1977-1979,89 \%$ (95\% CI $87-90 \%)$ for workers employed in 1980-1982, and $93 \%$ (95\% CI $91-94 \%$ ) for those employed in the latest period (1983-1985). The 7-year cumulative accident-free rates related to the same periods of employment were $57 \%$ (95\% CI 55-58\%), 67\% (95\% CI 64-70\%), and 73\% (95\% CI $70-76 \%)$, respectively. The curves for the 3 periods were significantly different $\left(c^{2} 2\right.$ df: 130 , $\mathrm{P}<0.001$ ).

Younger workers were more likely to have an injury than older workers (figure 1c). The difference in the injury-free rates between the youngest and the oldest age groups at the time of employment appeared to widen over time, being, at the end of the follow-up, $45 \%$ for the workers 1 st employed before 19 years of age and $56 \%$ for the workers employed at later ages.

There was a marked and statistically significant difference in the accident-free curves ( $\left.c^{2} 3 \mathrm{df}: 389, \mathrm{P}<0.001\right)$ according to educational level ( $£ 4,5-8,9-11,{ }^{3} 12$ years of school) (figure 1d). After 1 year of employment the probability of having had no injury for each educational group was $76 \%, 82 \%, 92 \%$ and $98 \%$, respectively, declining to $41 \%, 50 \%, 73 \%$, and $88 \%$ after 15 years. In relation to marital status, married workers had the better injury-free curve (figure 1e), followed by single workers and other marital statuses, respectively $\left(\mathrm{c}^{2} 2 \mathrm{df}: 19.5\right.$, $\mathrm{P}<0.001$ ).

Information on job category at the start of employment was available for 6407 workers in the cohort and missing for 86 . Sixty-three percent were laborers, $23 \%$ were clerical workers, and $12 \%$ were professional or technical workers. Job category was an important prognostic factor for being free of injury $\left(\chi^{2} 2 \mathrm{df}: 245\right.$, $\mathrm{P}<0.001)$. Laborers had the worst injury records with a probability of $80 \%$ for having had no injury in the 1st year $(95 \%$ CI $79-81 \%)$, compared with $87 \%$ (95\% CI $85-89 \%)$ and $95 \%(95 \%$ CI $94-97 \%)$ for clerical and professional workers, respectively (figure 1f).

Data on area of work within the plant at the start of employment were missing for 253 cohort members. For-
Table 1. Distribution of workers according to the number of occupational injuries recorded during the follow-up of the study population.

\begin{tabular}{lcc}
\hline Number of injuries & Number of workers & $\%$ \\
\hline 0 & 3807 & 58.6 \\
1 & 1573 & 24.2 \\
2 & 679 & 10.4 \\
3 & 244 & 3.8 \\
4 & 109 & 1.7 \\
5 & 45 & 0.7 \\
6 or more & 36 & 0.6 \\
\hline Total & 6493 & 100 \\
\hline
\end{tabular}

Table 2. Distribution of first injuries according to type of injury.

\begin{tabular}{lcc}
\hline Type of injury & Number & $\%$ \\
\hline Laceration, cuts & 967 & 36.0 \\
Contusion, hematoma & 514 & 19.1 \\
Foreign body & 422 & 15.7 \\
Burns, scalds, chemical burns & 298 & 11.1 \\
Sprains & 177 & 6.6 \\
Fractures & 130 & 4.8 \\
Poisoning & 50 & 1.9 \\
Multiple lesions & 48 & 1.8 \\
Chemical and light conjunctivitis & 47 & 1.8 \\
Other & 33 & 1.2 \\
\hline Total & 2686 & 100 \\
\hline
\end{tabular}

Table 3. Distribution of first injuries according to body site affected.

\begin{tabular}{lcr}
\hline Site of injury & Number of injuries & $\%$ \\
\hline Hands & 1055 & 39.3 \\
Eyes & 466 & 17.3 \\
Feet & 259 & 9.6 \\
Arms & 208 & 7.7 \\
Legs & 205 & 7.6 \\
Back & 132 & 4.9 \\
Face & 113 & 4.2 \\
Head \& neck & 36 & 1.3 \\
Other & 116 & 4.3 \\
Multiple sites & 96 & 3.6 \\
\hline Total & 2686 & 100 \\
\hline
\end{tabular}

ty percent of the employees were 1st employed in the administrative and production control areas, $37 \%$ holding the title of "apprentice" (workers who are still in the training stage, before final allocation to a job). The other $60 \%$ of the cohort was distributed into the 6 areas more directly related to the production process, and only $10 \%$ of them held the title of "apprentice". The relationship between 1st place of work and risk of injury was also significant ( $\chi^{2} 6$ df: $\left.137, P<0.001\right)$. Workers employed in administration and support had the best record, and those employed in the steel mill the worst, $88 \%(95 \%$ CI $87-89 \%$ ) being injury-free after 1 year in the former compared with $70 \%(95 \%$ CI $66-73 \%)$ after 1 year in the steel mill, and $81-84 \%$ after 1 year in the other areas of the plant. 

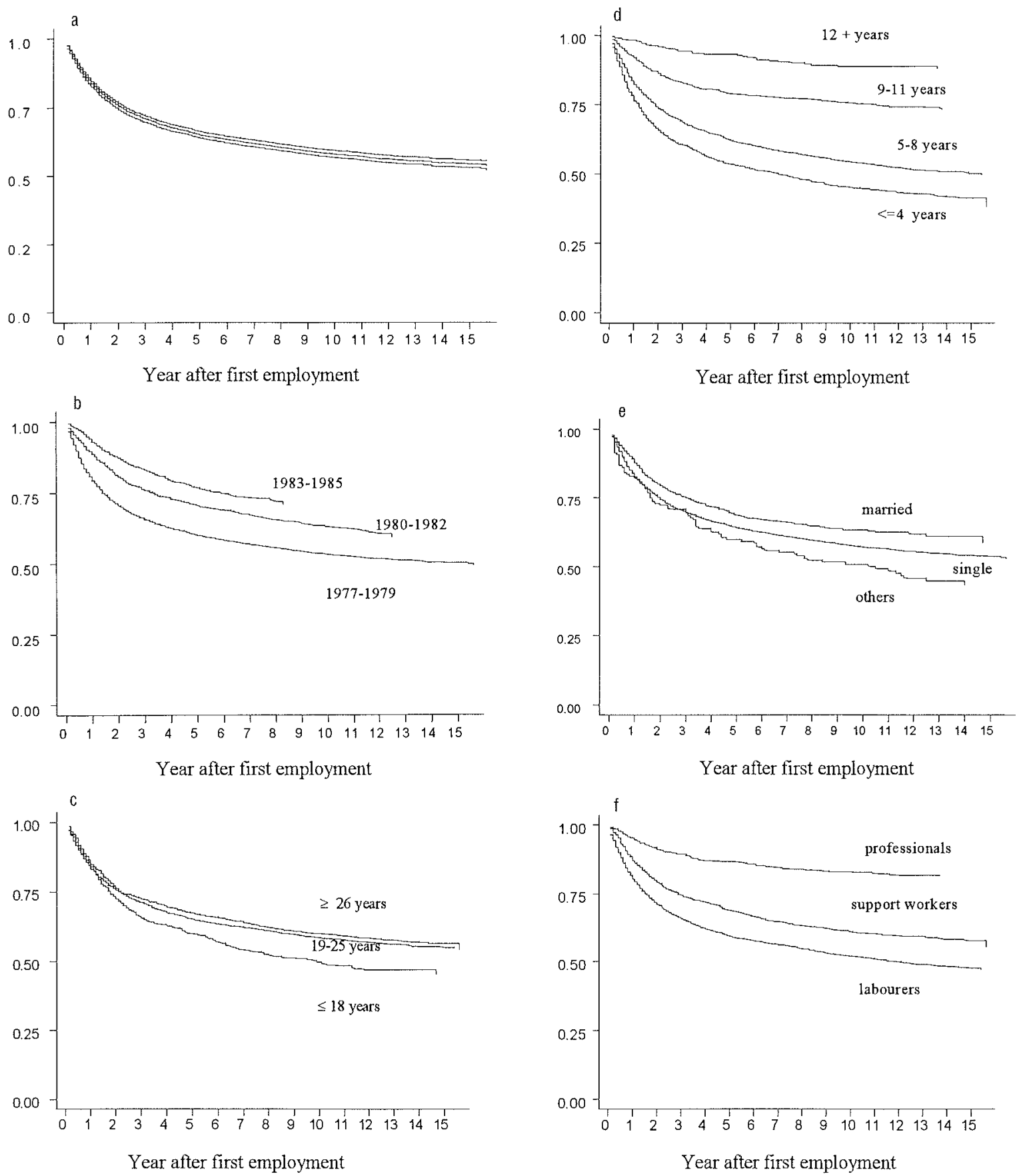

Figure 1. Kaplan-Meier estimates of proportion of workers remaining injury free at different times after 1st employment with the $95 \%$ confidence interval (a) and by the following selected characteristics at employment: period (b), age (c), education (d), marital status (e), and job category (f).

The multivariate Cox regression analysis showed that age and calendar period of start of employment, school level, 1st job category, and place of work were independent risk factors for nonfatal injury, but marital status was not related to risk after adjustment for the other factors $\left(\chi^{2} 2\right.$ df: $\left.0.67, P=0.72\right)$. In the final model (table 4), workers 1 st employed at the age of $\geq 19$ years had a more than $40 \%$ lower risk of occupational injury than those 1 st employed at younger ages. The risk decreased sig- nificantly and substantially between the workers starting employment in 1977-1979 and 1983-1985 $(\mathrm{P}<0.001)$. There was a highly significant inverse association between educational level and risk of injury $(\mathrm{P}<0.001)$. After adjustment for other factors, laborers remained significantly more likely than professional and technical workers to have an occupational injury [hazard ratio (HR) $1.76,95 \%$ CI 1.35-2.29]. The risk of injury varied only slightly between different areas of work, 
although there was a significantly increased risk for employees working in the steel mill area (HR $1.40,95 \% \mathrm{CI}$ $1.21-1.63$ ) and a significantly reduced risk for employees in energy supply (HR $0.79,95 \%$ CI $0.63-0.97$ ) and the crane and other motor vehicles category (HR 0.75 , $95 \%$ CI $0.60-0.94)$ than for those working in administration and production control.

\section{Discussion}

The probability of suffering an occupational injury in the 1 st year of employment was $16 \%$, increasing to $25 \%$ by the end of the 2 nd year. We identified the following 5 independent predictors of 1st nonfatal injury following employment in the steel plant: age and period of starting employment, school level, 1st job category, and work area.

The hazard ratios were inversely related to age and period at the start of employment. The highest risk was found for men aged $\leq 18$ years at the time of employment. Several studies have found an increased risk of occupational injury among younger workers $(1,2,16,17)$. A previous analysis of our cohort found that rates for fatal occupational injury were greatest among workers aged $<25$ years and $>45$ years and that mortality was highest in the 1st year of employment(10). In the United States, workers aged 16 and 17 years were at greater risk of death from occupational injury than older workers were (18). It is very difficult to separate out the effect of youth and inexperience as age is highly correlated with work experience. Younger and inexperienced workers might also be less able to respond to new hazards as they arise or might adopt risky behavior.

The substantial reduction in the risk of nonfatal injury for workers employed in later periods may be explained by increased automation and changes in the work organization. It may also reflect some improvement in safety strategies with time. There was a similar decrease in the rates of work-related injury in the country overall in the same period (5). Although records for this cohort were considered virtually complete, it is not possible to rule out some minor underreporting. It has been argued that safety incentives may have an indirect, but significant negative influence on the reporting of workplace injuries (19). The safety incentive program adopted in the steelworks during the study period was based on rewards for safety-related changes (barbecues, prizes, etc), and it therefore may have encouraged some underreporting. Nevertheless, any plausible change in the reporting rates in the period would not explain the sharp and steady declining trend in injury rates that we found for this cohort.

The increase in time to 1st injury with increased schooling may be partially explained by residual con-
Table 4. Factors associated with first occupational injury. (95\% $\mathrm{Cl}=95 \%$ confidernce interval)

\begin{tabular}{lll}
\hline Risk factor & Hazard ratio & $95 \% \mathrm{Cl}$ \\
\hline Age at start of employment (years) & & \\
$\leq 18$ & 1.00 & \\
$19-25$ & 0.59 & $0.51-0.69$ \\
$\geq 26$ & 0.56 & $0.47-0.68$ \\
& $\chi^{2}$ trend $=24.7$ & $\mathrm{P}<0.001$ \\
Period of start of employment & & \\
$1977-1979$ & 1.00 & \\
$1980-1982$ & 0.70 & $0.63-0.78$ \\
$1983-1985$ & 0.55 & $0.48-0.63$ \\
& $\chi^{2}$ trend $=101.6$ & $P<0.001$ \\
Years of schooling & & \\
$\geq 12$ & 1.00 & \\
9 & 2.05 & $1.36-3.09$ \\
$5-8$ & 3.50 & $2.27-5.39$ \\
< 4 & 4.18 & $2.69-6.49$ \\
First job category & $\chi^{2}$ trend $=73.1$ & $\mathrm{P}<0.001$ \\
Professional \& technical & 1.00 & \\
Support \& service & 1.13 & \\
Laborer & 1.76 & $0.86-1.49$ \\
First work area & & $1.35-2.29$ \\
Administration \& support & 1.00 & \\
Energy supply & 0.79 & $0.63-0.97$ \\
Maintenance & 0.97 & $0.83-1.13$ \\
Cranes \& motor vehicles & 0.75 & $0.60-0.94$ \\
Coke production & 0.86 & $0.73-1.00$ \\
Plate mill & 0.87 & $1.21-1.63$ \\
Steel mill & 1.40 & \\
\hline
\end{tabular}

after adjustment for all other factors in the table.

founding with job category, since adjustment was based on a crude categorization of jobs, and job title is highly correlated with level of education. We have previously found that lack of schooling was associated also with fatal work-related injuries (12). It is possible that education itself also plays a role in reducing injury risk, by increasing the awareness of risk among those who are better educated or promoting cautious attitudes towards hazards.

The finding of a significant increased risk of injury among the laborers, even after adjustment for education, is likely to reflect greater exposure to hazards in the workplace. The mortality rates for occupational injury were also greater for laborers in the same period (11). There are many unsafe areas in the steel plant, and the steel mill was the one associated with the greatest risk of injury. It is possible that less-skilled workers were more often employed in this area than in other producing areas. This area is the largest in the plant and areas that need less-skilled workers are concentrated there, for example, coal stock and primary ore and blending yards. The reverse, employment of more-skilled workers, may explain the lower risk observed for workers 1 st employed in the administration and support, energy supply, cranes and motor vehicles, coke production, and plate mill areas.

Using lost workdays to assess the severity of occupational injury may have seriously underestimated the 
magnitude of the problem in this study, since most workers with fractures, amputations of fingers, and other potentially serious injuries were temporarily assigned to other tasks or areas while recovering from their injury. This policy was aimed at reducing injury costs, and it also had a favorable impact on the apparent effectiveness of the injury prevention program adopted. An important goal of the ongoing program at that time was to reduce the number of lost-time injuries.

Although fractures accounted for only $4.8 \%$ of the $1 \mathrm{st}$ injuries (table 2), they often impair a worker's skill. In this study most of the fractures affected hands, arms, or legs. Nonlife threatening injuries, such as injuries to the hand and arms, resulting from accidents in the workplace were significant contributors to the prevalence of permanent injury-related disability among young adults in Great Britain (16).

We have restricted our investigation to time to 1 st injury using the Cox regression. An alternative method would have been to investigate time to injury with a frailty model (20) that would incorporate recurrent injuries. However, we have already addressed the issue of recurrent injury in an analysis of injury rates in this cohort (8) and found that newly employed workers had the highest rates of injury in the workplace. This was the rationale behind this analysis, in which we investigated factors that affected the time to 1st injury in a subset of newly employed workers for whom we could extract additional information on potential explanatory factors.

Unfortunately, the database available for our study had no information on the immediate antecedents of injuries. Such information is necessary for a more-detailed investigation of injury risks and would aid the design of strategies for injury prevention. However, knowledge of the populations at higher risk for various types and levels of severity of injuries is an important prerequisite for developing effective injury prevention programs.

\section{References}

1. McCaig LF, Burt CW, Stussman BJ. A comparison of workrelated injury visits and other injury visits to emergency departments in the United States, 1995-1996. J Occup Environ Med 1998;40:870-5.

2. Center for Disease Control and Prevention, Division of Safety Research, National Institute for Occupational Safety and Health. Surveillance for nonfatal occupational injuries treated in hospital emergency departments - United States, 1996. MMWR 1998;47:302-6.
3. National Institute for Occupational Safety and Health. Traumatic occupational injury research needs and priorities. Cincinnati $(\mathrm{OH})$ : National Institute for Occupational Safety and Health, 1998. DHHS (NIOSH) publication no, 98-134.

4. Leigh PJ, Markowitz SB, Fahs M, Shin C, Landrigan PJ. Occupational injury and illness in the United States: estimates of costs, morbidity, and mortality. Arch Intern Med 1997; 157:1557-68.

5. Frumkin $\mathrm{H}$, Camara $\mathrm{V}$ de M. Occupational health and safety in Brazil. Am J Public Health 1991;81:1619-24.

6. Wünsch Filho V. Variações e tendências na morbimortalidade dos trabalhadores. In: Monteiro CA, editor. Velhos e novos males da saúde no Brasil a evolucao do pais e de suas doencas. São Paulo: HUCITEC, NUPENS/USP, 1996:289-330.

7. Barker M, Power C. Disability in young adults: the role of injuries. J Epidemiol Community Health 1993;47:349-54.

8. Schoemaker MJ. Work related injuries: a cohort study of Brazilian steel workers. London: London School of Hygiene and Tropical Medicine, 1998.

9. Sahl JD, Kelsh MA, Haines KD, Sands FK, Kraus J. Acute injuries among electric utility meter readers. Epidemiology $1997 ; 8: 287-92$.

10. Cattledge GH, Schneiderman A, Stanevich R, Hendricks S, Greenwood J. Nonfatal occupational fall injuries in the West Virginia construction industry. Accid Anal Prev 1996;28:655-63.

11. Barreto SM, Swerdlow AJ, Smith PG, Higgins C, Andrade A. Mortality from injuries and other causes in a cohort of 21800 Brazilian steelworkers. Occup Environ Med 1996;53:34350 .

12. Barreto SM, Swerdlow AJ, Smith PG, Higgins C. Nested case-control study of fatal work-related injury among Brazilian steelworkers. Occup Environ Med 1997;54:599-604.

13. Barreto SM, Swerdlow AJ, Smith PG, Higgins C. Risk of death from motor-vehicle injury in Brazilian steel workers: a nested case-control study. Int J Epidemiol 1997;26:814-21.

14. Kleinbaum DG. Survival analysis: a self-learning text. New York (NY): Springer Verlag, 1997.

15. StataCorp. Stata Statistical Software: Release 5.0. College Station (TX): Stata Corporation, 1997.

16. Barker M, Power C, Roberts I. Injuries and the risk of disability in teenagers and young adults. Arch Dis Child 1996;75:156-8.

17. Kingma J. Causes of occupational injuries. Percept Mot Skills 1994;79:1025-6.

18. Castillo DN, Landen DD, Layne LA. Occupational injury deaths of 16- and 17-year-olds in the United States. Am J Public Health 1994;84(4):646--9.

19. Pransky G, Snyder T, Dembe A, Himmelstein J. Under-reporting of work-related disorders in the workplace: a case study and review of the literature. Ergonomics 1999;42:171 82.

20. Wassell JT, Wojciechowski WC, Landen DD. Recurrent injury event-time analysis. Stat Med 1999;18:3355-63.

Received for publication: 23 November 1999 